\section{ADHD Is Comorbid to Migraine in Childhood: A Population-Based Study}

\author{
Marco Antônio Arruda', Renato Arruda ${ }^{2}$, Vincenzo Guidetti ${ }^{3}$, \\ and Marcelo Eduardo Bigal $^{4}$
}

Journal of Attention Disorders $1-12$

(C) The Author(s) 2017

Reprints and permissions:

sagepub.com/journalsPermissions.nav DOI: 10.1 I77//0870547/77/0767

journals.sagepub.com/home/jad (S) SAGE

\begin{abstract}
Objective: Recurrent headaches and ADHD are prevalent in the pediatric population. Herein, we assess if ADHD is comorbid to headaches overall, to headache subtypes (e.g., migraine), and to headache frequency. Method: Informed consent and analyzable data were obtained for 5,67I children aged 5 to 12 years (65.9\% of the target sample). Parents and teachers were interviewed using validated questionnaires based on the Diagnostic and Statistical Manual of Mental Disorders (5th ed.; DSM-5). Relative risks were modeled using univariate and multivariate analyses. Results: As contrasted to nonheadache controls, the prevalence of ADHD was significantly higher in children with migraine $(p<.00 \mathrm{I})$ but not in those with tension-type headaches. In children with migraine, risk of ADHD increased as a function of headache frequency $(p<.05)$. Conclusion: Migraine and frequent migraine are comorbid to ADHD. Future studies should focus on the impact of the association on the burden to the children and their families. (J. of Att. Dis. $X X X X ; X X(X) X X-X X)$
\end{abstract}

\title{
Keywords
}

ADHD, migraine, comorbidity, children, epidemiology

\section{Introduction}

Migraine and ADHD are chronic prevalent disorders, each of them affecting up to $10 \%$ of children and adolescents worldwide (Abu-Arafeh, Razak, Sivaraman, \& Graham, 2010; Polanczyk, de Lima, Horta, Biederman, \& Rohde, 2007). Despite their distinct clinical features, both cause a sizable burden in different dimensions of the child's quality of life (Jonsson et al., 2017; Lee et al., 2016; Powers, Patton, Hommel, \& Hershey, 2003; Varni, Limbers, \& Burwinkle, 2007), mental health (Arruda \& Bigal, 2012a; Bellini et al., 2013; Inci, Ipci, Akyol Ardic, \& Ercan, 2016; Thapar \& Cooper, 2016), and school functioning (Arruda \& Bigal, 2012b; Fortes et al., 2016; Powers et al., 2003; Zendarski, Sciberras, Mensah, \& Hiscock, 2016).

The estimated burden of diseases rarely accounts for comorbidity (Gadermann, Alonso, Vilagut, Zaslavsky, \& Kessler, 2012) and even less for the complex mechanisms of association, where one disease may affect the natural history of the comorbid condition. The comorbidity of migraine and psychiatric conditions in the pediatric population is supported by clinical (Bruijn, Locher, Passchier, Dijkstra, \& Arts, 2010; Galli et al., 2007; Guidetti et al., 1998; Vannatta et al., 2008) and population-based studies (Arruda, Arruda, Guidetti, \& Bigal, 2015; Arruda \& Bigal, 2012a; Anttila et al., 2004; Virtanen et al., 2004). Children with migraine are more likely to have somatic, anxiety, and depressive symptoms compared with controls without headache. They are also more likely to be perceived as inattentive by their parents and teachers, relative to children without migraine (Arruda \& Bigal, 2012a).

The specific association between migraine and ADHD has been studied with conflicting results (Arruda, Guidetti, Galli, Albuquerque, \& Bigal, 2010b; Jameson et al., 2016). Furthermore, most studies studied the presence or absence of migraine and did not account for migraine subtypes, frequency of headaches, or other primary headaches (Jameson et al., 2016; Strine, Okoro, McGuire, \& Balluz, 2006). Few took advantage of ancillary information obtained by parents and teachers (Arruda et al., 2010a).

The comorbidity between ADHD and migraine may be justified by plausible biological mechanisms, including dopamine dysregulation, abnormalities of the hypothalamic-pituitary-adrenal axis, and genetic factors and brain iron metabolism (Parisi et al., 2014).

Herein, we take advantage of a nationwide epidemiological study (Attention Brazil Project) where children were

\footnotetext{
'Glia Institute, Ribeirão Preto, Brazil

${ }^{2}$ State University of Campinas, Brazil

${ }^{3}$ Sapienza University of Rome, Italy

${ }^{4}$ Teva Pharmaceuticals Research and Development, Frazer, PA, USA

Corresponding Author:

Marco Antônio Arruda, Glia Institute, Av. Braz Olaia Acosta, 727, s. 310 , Ribeirão Preto, SP I4026-040, Brazil.

Email:arruda@institutoglia.com.br
} 
identified at schools, and parents and teachers were interviewed with validated questionnaires based on standardized diagnostic criteria, to investigate the comorbidity between ADHD and primary headaches (migraine and tension-type headache), as well as the influence of headache frequency in this association.

\section{Method}

\section{Overview}

This is a cross-sectional study from a nation-based project designed to establish inception cohorts for studying factors that may affect learning and mental health of children and adolescents in Brazil (Attention Brazil Project). A pilot study was initially conducted where all children from 5 to 12 years of age $(n=2,173)$ who registered in the public school system of a city (Santa Cruz das Palmeiras, SP, Brazil) were selected, and their mothers and teachers were interviewed (Arruda \& Bigal, 2012a; Arruda, Guidetti, Galli, Albuquerque, \& Bigal, 2010a). The pilot phase defined the validated questionnaires that would be used in the nationwide phase presented herein.

The project was developed in a nonprofit virtual academic network that started in 2006 called Aprender Crianca (Learning Child; www.aprendercrianca.com.br). Currently, about 6,500 members are registered in the organization, with $86 \%$ of them being teachers, psychologists, and medical doctors among other related professions.

\section{Flow of the Study}

All members of the organization teaching in the elementary public school system were invited through email to voluntarily participate in the study. A total of 124 of them were randomly selected to participate in this study. They were individually trained on how to interview the mothers of the sample. They were also instructed to fill out their questionnaire providing information about the student's behavior and educational achievements, as described below. All teachers completed a $4-\mathrm{hr}$ online training provided by one of us (M.A.A.).

Children from urban and rural areas were assessed, as long as they were enrolled in the school system (which is mandatory). Of the 8,599 children being educated by the participating teachers $(M=69.3$ students/teacher or 34.6/ teacher/day period), parental consents were obtained from $6,445(75 \%)$ and analyzable data (complete demographic, mental health, and headache information) from 5,671 $(65.9 \%)$. All of them were of 5 to 12 years of age $(50.7 \%$ boys). They were enrolled from 87 cities in 18 Brazilian states under the five national regions (Instituto Brasileiro de Geografia e Estatística, 2009).

\section{Assessments}

Information obtained from the teachers. Before conducting mothers' interviews, teachers completed the Brazilianvalidated version of the Multimodality Treatment Study Swanson, Nolan e Pelham - version IV (MTA-SNAP-IV) scale for each child (Mattos, Serra-Pinheiro, Rohde, \& Pinto, 2006). This scale was designed to assess the presence of ADHD symptoms according to the Diagnostic and Statistical Manual of Mental Disorders (5th ed.; DSM-5; American Psychiatric Association [APA], 2013).

Teachers were then asked to provide information on the student school performance, with measurements of the overall achievement for the school year derived from competencies in language, mathematics, science, and social studies. Children were ranked as below expectations (failed to achieve a minimal number of established milestones for the year), matching expectations, or above expectations (achieved milestones only expected to be achieved in the following school year) for the grade in accordance with the education board standards.

Information obtained from the mothers. Mothers were then interviewed by the teachers using a standardized questionnaire with 102 questions assessing sociodemographic features, past medical history of the child, headaches, and mental health.

The headache module of the questionnaire consisted of 14 questions, assessing the distinguishing features required for headache diagnosis of the children according to the Second Edition of the International Classification of Headache Disorders (ICHD-2; Headache Classification Subcommittee of the International Headache Society, 2004) such as frequency and duration of the attacks, headache characteristics, associated symptoms, and consumption of analgesics, and behaviors related to pain. The questionnaire is the validated Brazilian Portuguese version of the questionnaire used in the American Migraine Studies (Lipton, Diamond, Reed, Diamond, \& Stewart, 2001), and has been extensively used in pediatric and adult studies in Brazil (Arruda \& Bigal, 2012a; Queiroz et al., 2008).

\section{Headache Diagnosis}

Based on the response to the questionnaires, headache diagnoses were assigned. Migraine was subdivided into episodic (EM) and chronic migraine (CM), and the same approach was used for tension-type headache (ETTH and CTTH). Probable migraine and probable TTH were excluded due to the overlapping features of migraine and TTH in young children (Arruda, Bordini, Ciciarelli, \& Speciali, 2004). Children with no headaches did not endorse criteria for any primary headaches (including probable diagnoses). For children with more than one headache type, we focused on the most severe type. 


\section{ADHD Diagnosis}

ADHD was assessed according to DSM-5 (APA, 2013) criteria using the MTA-SNAP-IV (Mattos et al., 2006) scale and the validated Brazilian version of the Strengths and Difficulties Questionnaire (SDQ) added to the impact supplement (Fleitlich \& Goodman, 2001; Goodman, 1999; Goodman et al., 2005). The SDQ is a 25 -item instrument developed to assess characteristics of psychosocial adjustment from the perspective of the individual (if adolescents or adults), or from the perspective of parents or teachers (if younger children). The SDQ consists of five scales, each of them with five items assessing emotional symptoms, conduct problems, hyperactivity/inattention, peer problems, and prosocial behavior problems. The mothers filled out the SDQ parental version as well as the impact supplement related to any adjustment symptom in terms of chronicity, resultant distress, social impairment, or burden for others, a compulsory criterion for the diagnosis of ADHD according to DSM-5 (APA, 2013).

The MTA-SNAP-IV scale consists of 18 items, each one corresponding to the 18 symptoms of ADHD in accordance with the DSM-5 (APA, 2013) criteria.

\section{Analyses}

Data were described using summary tables and descriptive statistics. The demography of the participants was described as a function of ADHD and headache status stratification.

Race was divided into three categories: White, nonWhite, and nonrespondents. The five income classes were defined according to the Brazilian Economic Classification Criteria which are determined based on a combination of variables such as consumption of certain goods, household characteristics, and so on (Associação Brasileira de empresas de pesquisa, 2009). These criteria were developed as an income predictor by estimating a classic Mincerian income regression to define the final income classes, leading to a classification based on expected current income and not on the theoretical concept of permanent income (Mincer, 1958).

Sex-specific prevalence estimates of primary headaches (1-year period prevalence) were derived by age. Crude and adjusted prevalence ratios were obtained using binary regression model. Prevalence ratios and 95\% confidence intervals compared specific categories (e.g., age categories, or race) with the reference category.

$A D H D$ as a function of headache frequency. We defined ADHD as a dichotomous variable (present or not) and first correlated it with headache diagnosis using linear regression or Spearman's correlation. To assess the influence of headache frequency on ADHD, we then stratified migraine as a function of the monthly headache frequency as follows: (a) less than 5 days of headache per month, (b) from 5 to 9 days of headache per month, (c) from 10 to 14 days of headache per month, and (d) more than 14 days of headache per month.

Multivariate analysis. Logistic regression was used to model the log odds of the dichotomous outcome variable (having ADHD and migraine or not) as a linear combination of the predictor variables. The variables included in the model were demographics (age, gender, race, income class, city density, and national region where a child lives), prenatal exposure to tobacco and alcohol, headache frequency, and school performance. Interaction was tested in the model.

The level of significance adopted was 5\%. Statistical analysis was performed using SPSS 15.0 for Windows (SPSS Inc.; Chicago, IL).

\section{Investigation Review Board Approval}

This study and surveys received full approval from a Human Research Committee (School of Medicine at Sao Jose do Rio Preto, State University of Sao Paulo, Brazil). A written informed consent was discussed with and obtained from the parents (or from the guardians of the children).

\section{Results}

\section{Overview}

Among the participant sample, analyzable data were obtained from 5,671 children. Table 1 displays the demographics of the participating sample and of those without complete data. Overall, participation rate was approximately $75 \%$, and complete data were obtained from $66 \%$ of the target sample (and $88 \%$ of those who consented). About $51 \%$ of respondents were boys, and $50 \%$ were from the middle class (Class $\mathrm{C}$ ).

Participation was remarkably uniform as a function of demographics and of school year. It was similar across regions of the country but the proportion of participants with analyzable data varied, being higher in the most developed regions of the country, likely reflecting educational status of the mothers.

\section{Prevalence of Headaches and ADHD}

Table 2 displays the prevalence of migraine, TTH, and ADHD by demographics. EM was diagnosed in $9 \%$ of the sample ( $9.6 \%$ of girls and $8.4 \%$ of boys), being more prevalent in children aged 9 to 12 years relative to those aged 5 to $8(11.2 \%$ vs. $7.2 \%$, relative risk $[R R]=1.6,95 \%$ confidence interval $[\mathrm{CI}]=[1.3,1.8])$. CM occurred in $0.6 \%$ of the sample, overall and by gender, with a higher prevalence in children aged 9 to $12(0.9 \%$ vs. $0.4 \%, \mathrm{RR}=2.1,95 \% \mathrm{CI}=[1.1$, 
Table I. Target Sample, Respondents, and Final Sample According to Demographic Features.

\begin{tabular}{|c|c|c|c|c|c|c|c|}
\hline & \multirow[b]{2}{*}{ Target sample } & \multirow{2}{*}{\multicolumn{2}{|c|}{ Consented }} & \multirow{2}{*}{\multicolumn{2}{|c|}{ Final sample }} & \multicolumn{2}{|c|}{ Participation rate } \\
\hline & & & & & & \multirow{2}{*}{$\begin{array}{c}\begin{array}{c}\text { Relative to } \\
\text { target sample }\end{array} \\
\%\end{array}$} & \multirow{2}{*}{$\begin{array}{c}\text { Relative to } \\
\text { consented }\end{array}$} \\
\hline & $n$ & $n$ & $\%$ & $N$ & $\begin{array}{l}\text { Weighted \% } \\
(95 \% \mathrm{Cl})\end{array}$ & & \\
\hline \multicolumn{8}{|l|}{ Age group } \\
\hline $5-8$ & 4,801 & 3,657 & 76.2 & 3,111 & $54.9[53.6,56.1]$ & 64.8 & 85.1 \\
\hline $9-12$ & 3,798 & 2,788 & 73.4 & 2,560 & $45.1[43.8,46.4]$ & 67.4 & 91.8 \\
\hline \multicolumn{8}{|l|}{ Gender } \\
\hline Female & 4,259 & 3,186 & 74.8 & 2,794 & $49.3[48.0,50.1]$ & 65.6 & 87.7 \\
\hline Male & 4,340 & 3,259 & 75.1 & 2,877 & $50.7[49.4,52.0]$ & 66.3 & 88.3 \\
\hline \multicolumn{8}{|l|}{ School year } \\
\hline 1 & 1,538 & 1,160 & 75.4 & 1,044 & $18.4[17.4,19.4]$ & 67.9 & 90.0 \\
\hline 2 & 2,384 & 1,884 & 79.0 & 1,674 & $29.5[28.3,30.7]$ & 70.2 & 88.9 \\
\hline 3 & 1,716 & 1,252 & 73.0 & $\mathrm{I}, 105$ & $19.5[18.5,20.5]$ & 64.4 & 88.3 \\
\hline 4 & 2,053 & 1,490 & 72.6 & $\mathrm{I}, 272$ & $22.4[21.3,23.5]$ & 62.0 & 85.4 \\
\hline 5 & 908 & 659 & 72.6 & 576 & $10.2[9.4,11.0]$ & 63.4 & 87.4 \\
\hline \multicolumn{8}{|l|}{ Race } \\
\hline White & 5,856 & 4,198 & 71.7 & 3,769 & $66.5[65.2,67.7]$ & 64.4 & 89.8 \\
\hline Non-White & 2,743 & 1,964 & 71.6 & 1,672 & $29.5[28.3,30.7]$ & 61.0 & 85.1 \\
\hline Nonrespondents & & 283 & & 230 & 4.I $[3.6,4.6]$ & & 81.3 \\
\hline \multicolumn{8}{|l|}{ Income class ${ }^{\mathrm{a}}$} \\
\hline$A, B$ & 3,034 & 2,332 & 76.9 & 2,069 & $36.5[35.2,37.7]$ & 68.2 & 88.7 \\
\hline C & 4,347 & 3,234 & 74.4 & 2,856 & $50.4[49.1,51.7]$ & 65.7 & 88.3 \\
\hline$D, E$ & 1,218 & 879 & 72.2 & 746 & $13.2[12.3,14.1]$ & 61.2 & 84.9 \\
\hline \multicolumn{8}{|l|}{ Region } \\
\hline North & 278 & 172 & 61.9 & 134 & $2.4[2.0,2.8]$ & 48.2 & 77.9 \\
\hline Northeast & 1,245 & 912 & 73.3 & 712 & I2.6 [II.7, |3.5] & 57.2 & 78.1 \\
\hline Midwest & 405 & 298 & 73.6 & 188 & $3.3[2.9,3.8]$ & 46.4 & 63.1 \\
\hline Southeast & 3,778 & 2,837 & 75.1 & 2,542 & $44.8[43.5,46.1]$ & 67.3 & 89.6 \\
\hline South & 2,893 & 2,226 & 76.9 & 2,095 & $36.9[35.7,38.2]$ & 72.4 & 94.1 \\
\hline \multicolumn{8}{|l|}{ Population density } \\
\hline$<100,000$ & 3,245 & 2,567 & 79.1 & 2,220 & $39.1[37.9,40.4]$ & 68.4 & 86.5 \\
\hline $100,000-500,000$ & 3,546 & 2,589 & 73.0 & 2,365 & $41.7[40.4,43.0]$ & 66.7 & 91.3 \\
\hline$>500,000$ & 1,808 & 1,289 & 71.3 & 1,086 & $19.2[18.1,20.2]$ & 60.1 & 84.3 \\
\hline Total & 8,599 & 6,445 & 75.0 & $5,67 \mid$ & 100.0 & 65.9 & 88.0 \\
\hline
\end{tabular}

Note. $\mathrm{Cl}=$ confidence interval.

ancome classes defined according to the Brazilian Economic Classification Criteria (Associação Brasileira de empresas de pesquisa, 2009).

$4.2])$, and in children from poorest income classes $(\mathrm{D} / \mathrm{E})$ compared with those from the wealthiest $(1.2 \%$ vs. $0.3 \%$, $\mathrm{RR}=4.2,95 \% \mathrm{CI}=[1.5,11.6])$. ETTH was diagnosed in $12.8 \%$ of the sample, with a lower prevalence in children from the poorest income classes (D/E) compared with the wealthiest $(8.6 \%$ vs. $14.4 \%, \mathrm{RR}=0.6,95 \% \mathrm{CI}=[0.5,0.8])$.

The overall prevalence of ADHD was $5.3 \%$, being significantly higher in boys $(7.5 \%$ vs. $3.1 \%$ girls, $\mathrm{RR}=2.4$, $95 \% \mathrm{CI}=[1.9,3.1])$ and in non-White $(6.5 \%$ vs. $4.8 \%$ White, $\mathrm{RR}=1.3,95 \% \mathrm{CI}=[1.1,1.7])$. Higher risks were found when comparing different income classes. The poorest children (Classes D/E) were more than twice as likely as the wealthiest $(\mathrm{A} / \mathrm{B})$ to meet $D S M-5$ criteria for ADHD
$(\mathrm{RR}=2.4,95 \% \mathrm{CI}=[1.7,3.3])$. Compared with children of highest income, those of middle class (C) showed a higher risk of $\mathrm{ADHD}(\mathrm{RR}=1.5,95 \% \mathrm{CI}=[1.1,1.9]$; Table 2$)$.

\section{ADHD as a Function of Headache Diagnosis- Univariate Analyses}

Table 3 displays the prevalence of ADHD, hyperactivityimpulsivity, and inattention (as separate domains of ADHD symptoms) as a function of headache diagnosis. As contrasted to controls, prevalence of ADHD was significantly higher in children with migraine overall (10.8\% vs. $2.6 \%$, $\mathrm{RR}=4.1,95 \% \mathrm{CI}=[2.7,6.2]), \mathrm{EM}(10.2 \%$ vs. $2.6 \%$, 
Table 2. Prevalence of ADHD and Primary Headaches as a Function of Demographics.

\begin{tabular}{|c|c|c|c|c|c|c|c|c|c|c|}
\hline & \multicolumn{2}{|c|}{ ADHD } & \multicolumn{2}{|c|}{ Episodic migraine } & \multicolumn{2}{|c|}{ Chronic migraine } & \multicolumn{2}{|c|}{ Episodic TTH } & \multicolumn{2}{|c|}{ Chronic TTH } \\
\hline & $n(\%)$ & $\mathrm{RR}(95 \% \mathrm{Cl})$ & $n(\%)$ & $\mathrm{RR}(95 \% \mathrm{Cl})$ & $n(\%)$ & $\mathrm{RR}(95 \% \mathrm{Cl})$ & $n(\%)$ & $\mathrm{RR}(95 \% \mathrm{Cl})$ & $n(\%)$ & $\mathrm{RR}(95 \% \mathrm{Cl})$ \\
\hline \multicolumn{11}{|l|}{ Age group } \\
\hline $5-8$ & $156(5.0)$ & Reference & $223(7.2)$ & Reference & $13(0.4)$ & Reference & $404(13.0)$ & Reference & I $(0.0)$ & Reference \\
\hline $9-12$ & I47 (5.7) & I.I $[0.9,1.4]$ & $287(1 \mathrm{I} .2)$ & I.6 [1.3, I.8] & $23(0.9)$ & 2.I [I.I, 4.2] & $322(12.6)$ & $\mathrm{I} .0[0.8, \mathrm{I} . \mathrm{I}]$ & $0(0.0)$ & $0.4[0.0,9.9]$ \\
\hline \multicolumn{11}{|l|}{ Gender } \\
\hline Female & $87(3.1)$ & Reference & $268(9.6)$ & Reference & $18(0.6)$ & Reference & $357(12.8)$ & Reference & $0(0.0)$ & Reference \\
\hline Male & $216(7.5)$ & $2.4[1.9,3.1]$ & $242(8.4)$ & $0.9[0.7,1.0]$ & $18(0.6)$ & $1.0[0.5,1.9]$ & $369(12.8)$ & $1.0[0.9,1.1]$ & I $(0.0)$ & $2.9[0.1,71.5]$ \\
\hline \multicolumn{11}{|l|}{ Race } \\
\hline White & $182(4.8)$ & Reference & $338(9.0)$ & Reference & $23(0.6)$ & Reference & $516(13.7)$ & Reference & I $(0.0)$ & Reference \\
\hline Non-White & $109(6.5)$ & I.3 [1.1, I.7] & $158(9.4)$ & $1.0[0.9,1.3]$ & $9(0.5)$ & $0.9[0.4,1.9]$ & $184(11.0)$ & $0.8[0.7,0.9]$ & $0(0.0)$ & $0.7[0.0,18.4]$ \\
\hline Nonrespondents & $12(5.2)$ & I.I [0.6, I.9] & $14(6.1)$ & $0.7[0.4,1.1]$ & $4(1.7)$ & $2.8[1.0,8.2]$ & $26(11.3)$ & $0.8[0.6,1.2]$ & $0(0.0)$ & $5.4[0.2,133.1]$ \\
\hline \multicolumn{11}{|l|}{ Income class } \\
\hline$A, B$ & $78(3.8)$ & Reference & $162(7.8)$ & Reference & $6(0.3)$ & Reference & $297(14.4)$ & Reference & I $(0.0)$ & Reference \\
\hline $\mathrm{C}$ & $158(5.5)$ & I.5 [I.I, I.9] & $274(9.6)$ & I.2 [I.0, I.5] & $2 \mathrm{I}(0.7)$ & $2.5[1.0,6.3]$ & $365(12.8)$ & $0.9[0.8,1.0]$ & $0(0.0)$ & $0.2[0.0,5.9]$ \\
\hline$D, E$ & $67(9.0)$ & $2.4[1.7,3.3]$ & $74(9.9)$ & I.3 [1.0, I.6] & $9(1.2)$ & $4.2[1.5,11.6]$ & $64(8.6)$ & $0.6[0.5,0.8]$ & $0(0.0)$ & $0.9[0.0,22.6]$ \\
\hline Total & $303(5.3)$ & & $510(9.0)$ & & $36(0.6)$ & & $726(12.8)$ & & I $(0.0)$ & \\
\hline
\end{tabular}

Note. $\mathrm{TTH}=$ tension-type headache; $\mathrm{RR}=$ relative risk; $\mathrm{Cl}$ = confidence interval.

$\mathrm{RR}=3.8,95 \% \mathrm{CI}=[2.5,5.9])$, and $\mathrm{CM}(19.4 \%$ vs. $2.6 \%$, $\mathrm{RR}=7.3,95 \% \mathrm{CI}=[3.5,15.5])$. No significantly different prevalences were observed for children with TTH relative to children without headaches. Similar findings were observed for the prevalence of hyperactivity-impulsivity and inattention symptoms as a function of headache diagnosis. The prevalence of hyperactivity-impulsivity symptoms was $5.6 \%$ in controls, $10.6 \%$ in children with migraine overall $(\mathrm{RR}=1.9,95 \% \mathrm{CI}=[1.4,2.7]), 10.2 \%$ for $\mathrm{EM}(\mathrm{RR}$ $=1.8,95 \% \mathrm{CI}=[1.3,2.6])$, and $16.7 \%$ for $\mathrm{CM}(\mathrm{RR}=3.0$, $95 \% \mathrm{CI}=[1.4,6.5])$. The prevalence of inattention symptoms was $4.8 \%$ in controls, $10.3 \%$ in children with migraine overall $(\mathrm{RR}=2.1,95 \% \mathrm{CI}=[1.5,3.1]), 9.6 \%$ for $\mathrm{EM}(\mathrm{RR}$ $=2.0,95 \% \mathrm{CI}=[1.4,2.9])$, and $19.4 \%$ for $\mathrm{CM}(\mathrm{RR}=4.1$, $95 \% \mathrm{CI}=[2.0,8.3])$. Again, the prevalence of hyperactivity-impulsivity and inattention was not significantly different in children with TTH, ETTH, or CTTH relative to children without headaches.

Of the 59 children diagnosed with ADHD and migraine, only two were taking psychostimulants; however, none of them fulfilled the diagnostic criteria for headache as an adverse event attributed to chronic medication according to the ICHD-2.

\section{Multivariate Analyses}

As migraine but not TTH was associated with ADHD, we focused on the influence of headache frequency on children with migraine only (Table 4). Analyses are limited by the skewed distribution of headache frequency (toward low frequency headaches). Nonetheless, the point prevalence of ADHD increased as a function of headache frequency and achieved statistical significance in children with CM compared with those with less than five migraine attacks per month $(\mathrm{RR}=2.1,95 \% \mathrm{CI}=[1.01,4.3], p=.04)$. For inattention symptoms, the prevalence was significantly higher only comparing children with 10 to 14 migraine attacks per month with those with less than five $(23.0 \%$ vs. $10.5 \%$, RR $=2.2,95 \% \mathrm{CI}=[1.03,4.7])$. No significant difference was found comparing the prevalence of hyperactivity-impulsivity symptoms between the groups (Table 4).

Direct logistic regression was performed to assess the impact of several variables on the migraine/ADHD association (Table 5). The relationship was held true after the adjustments $(p<.000)$. Variables making unique statistically significant contribution to the final model included gender, prenatal exposure to tobacco, below expectation school performance (failed to achieve a minimal number of established milestones for the year), and headache frequency. The strongest predictors were frequency of migraine attacks $(\mathrm{RR}=11.7,95 \% \mathrm{CI}=[5.4,25.4])$ and below expectation school performance $(\mathrm{RR}=8.1,95 \%$ $\mathrm{CI}=[4.1,16.0])$. Children with migraine and more than eight headaches per month and having school performance issues were more than 8 times more likely to have ADHD than those who did not, after controlling for all other factors in the model (Table 5).

\section{Discussion}

Although our study did not focus on the prevalence of headaches but on their comorbidity with ADHD, the prevalence rates found by us are aligned with the headache (Abu-Arefeh \& Russell, 1994) and ADHD (Polanczyk et al., 2007) pediatric studies. Our findings can be summarized as follows: (a) ADHD overall, as well as hyperactivity-impulsivity and inattention were comorbid with migraine but not with TTH; (b) the risk of comorbidity is higher in children with CM; (c) 


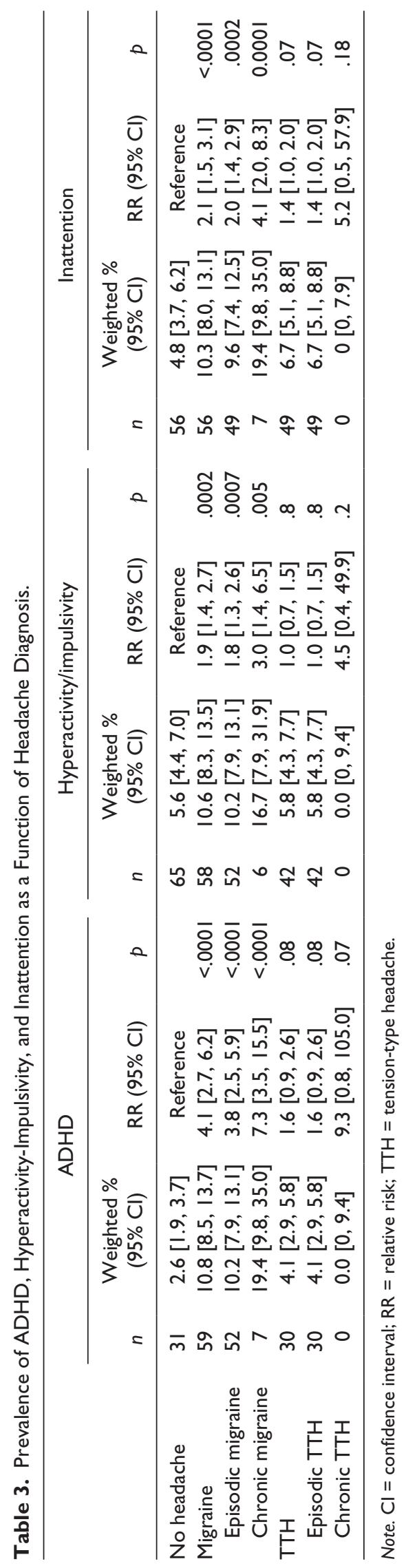




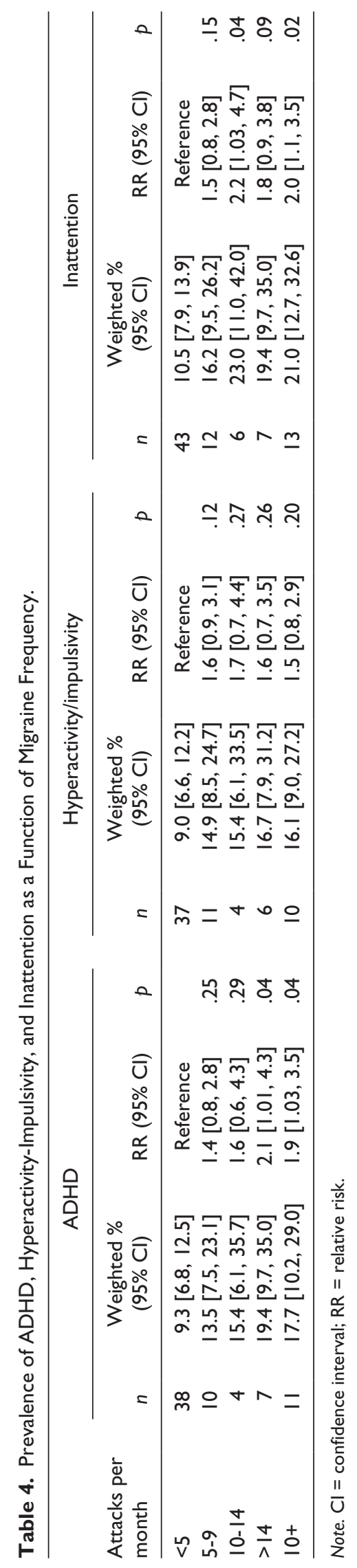




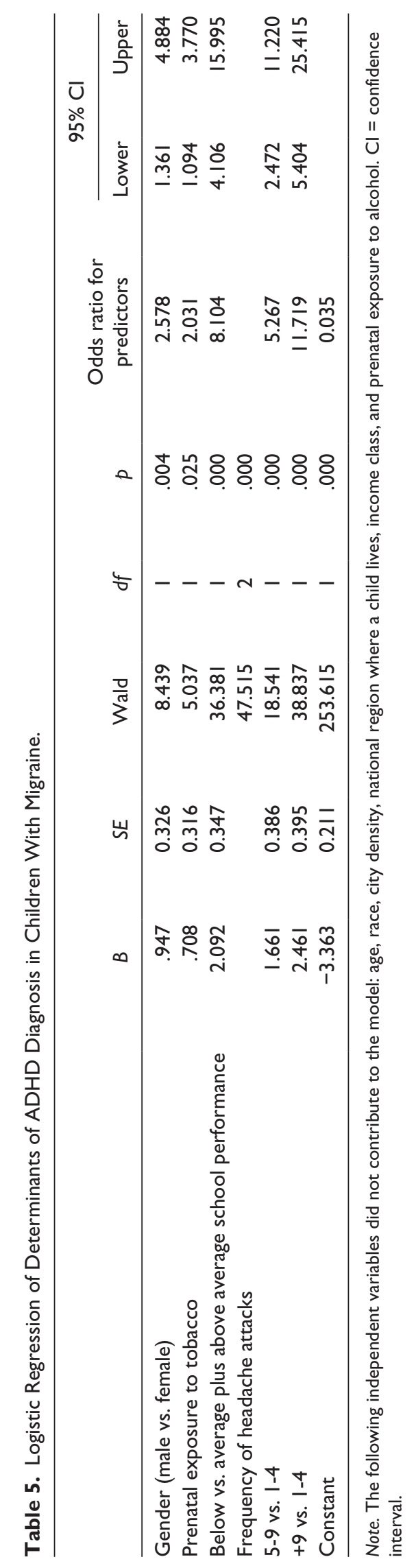


a number of risk factors to the association were identified, including male gender, prenatal exposure to tobacco, headache frequency, and below average school performance. These results confirm prior clinical observations without the limitations of clinic-based studies (Fasmer, Halmoy, Oedegaard, \& Haavik, 2011; Jameson et al., 2016).

In the pilot, smaller phase of this project, we failed to identify the association between migraine and ADHD. However, less restrictive criteria were used for the diagnoses of both ADHD and headaches. For ADHD, instead of requiring at least six symptoms of inattention and/or hyperactivityimpulsivity, as recommended by the Diagnostic and Statistical Manual of Mental Disorders (4th ed.; DSM-IV; APA, 1994), we used at least two (meeting the DSM-IV pervasiveness criterion across home and school), which resulted in a higher prevalence rate of ADHD (6.1\%; Arruda et al., $2010 \mathrm{~b}$ ). We also included probable diagnoses of migraine and TTH. As the ICHD-2 criteria for probable diagnoses have very little specificity in the pediatric population, as found by following these children for 16 months (Arruda et al., 2004), herein we excluded probable diagnoses.

The pathophysiology of ADHD and migraine is still not fully understood. However, dopamine dysregulation (Treister, Eisenberg, Demeter, \& Pud, 2015) and an abnormal functioning of the hypothalamic-pituitary-adrenal axis (Scherder, Rommelse, Broring, Faraone, \& Sergeant, 2008) have been suggested as a possible link between them, as well as genetic factors and brain iron metabolism (Parisi et al., 2014). Accordingly, the association does have biological plausibility.

Migraine, but not headaches overall, is comorbid to a variety of other conditions, including obesity (Bigal \& Lipton, 2006), asthma (Lateef et al., 2009; Peng et al., 2016), cerebrovascular (Gelfand et al., 2015) and cardiovascular diseases (Bigal et al., 2010), epilepsy (Kelley, Hartman, \& Kossoff, 2012; Ottman \& Lipton, 1994), and Tourette Syndrome (Kwak, Vuong, \& Jankovic, 2003).

There exist conflicting data on the comorbidity of migraine and TTH with internalizing (depressive, anxiety, and somatic) symptoms in childhood, with part of the studies advocating an exclusive association with migraine, and others showing the association with both, with a higher risk in migraine additionally influenced by the frequency of the attacks (Arruda et al., 2015; Arruda \& Bigal, 2012a).

In the present study, the frequency of headaches among children with migraine clearly increased the risk of having ADHD, a fact that was also found by a number of other comorbidities, including temporomandibular disorder (Goncalves, Speciali, Jales, Camparis, \& Bigal, 2009) and obesity (Bigal \& Lipton, 2006). Our findings are also supported by adult data, where individuals with ADHD had higher odds of experiencing chronic pain (Stickley, Koyanagi, Takahashi, \& Kamio, 2016) and using pain medications (Vingilis et al., 2015), as well as a significantly shorter cold pain threshold and cold tolerance (Treister et al., 2015). Longitudinal studies on the directionality of these comorbidities are necessary for a better understanding of the pathophysiological links between the involved disorders.

Strengths and limitations of our study deserve comment. Among the strengths, we list the population nature of our study, the large sample size of preadolescents, the use of validated questionnaires in direct interviews with the mother and the teacher, the strict adherence to standardized criteria for ADHD and headache diagnosis, and the multivariate adjustments.

Among the limitations, we highlight that headache diagnosis was reported and not based on diaries. However, this is not different from what is often seen in medical practice for young children, and potential biases of our method need to be explored (Arruda et al., 2004). Second, we likely underestimated the prevalence of the ETTH, as we only classified the most severe type of headache presented by the child. Nonetheless, in the literature, the prevalence of two or more headaches is not yet clear in children as is well established in adults. Third, we did not differentiate between migraine with or without aura based on the difficult to distinguish aura from photophobia in young children, specially relying only on the information given by the mother and not a direct medical evaluation. Fourth, the ancillary information for the diagnosis of ADHD and migraine was obtained from the mothers not from the children directly. Although this is a limitation, this is not substantially different than how medication would be ascertained in a pediatric consult.

Migraine and frequent migraine are comorbid to ADHD overall, as well as with hyperactivity-impulsivity and inattention. Future studies should focus on the impact of the association on the burden to the children and their families. Until then, we suggest that when attending children with headaches, clinicians should explore school performance, absenteeism, and mental health (especially symptoms such as inattention, hyperactivity, and impulsivity). Special focus should be given to male children with high frequency of headache attacks.

\section{Declaration of Conflicting Interests}

The author(s) declared no potential conflicts of interest with respect to the research, authorship, and/or publication of this article.

\section{Funding}

The author(s) received no financial support for the research, authorship, and/or publication of this article.

\section{References}

Abu-Arafeh, I., Razak, S., Sivaraman, B., \& Graham, C. (2010). Prevalence of headache and migraine in children and adolescents: A systematic review of population-based studies. Developmental Medicine \& Child Neurology, 52, 1088-1097. doi:10.1111/j.1469-8749.2010.03793.x 
Abu-Arefeh, I., \& Russell, G. (1994). Prevalence of headache and migraine in schoolchildren. British Medical Journal, 309, 765-769.

American Psychiatric Association. (1994). Diagnostic and statistical manual of mental disorders (4th ed.). Washington, DC: Author.

American Psychiatric Association. (2013). Diagnostic and statistical manual of mental disorders (5th ed.). Arlington, VA: American Psychiatric Publishing.

Anttila, P., Sourander, A., Metsahonkala, L., Aromaa, M., Helenius, H., \& Sillanpaa, M. (2004). Psychiatric symptoms in children with primary headache. Journal of the American Academy of Child \& Adolescent Psychiatry, 43, 412-419. doi:10.1097/00004583-200404000-00007

Arruda, M. A., Arruda, R., Guidetti, V., \& Bigal, M. E. (2015). Psychosocial adjustment of children with migraine and tension-type headache-A nationwide study. Headache, 55(Suppl. 1), 39-50. doi:10.1111/head.12510

Arruda, M. A., \& Bigal, M. (2012a). Behavioral and emotional symptoms and primary headaches in children: A population-based study. Cephalalgia, 32, 1093-1100. doi: $10.1177 / 0333102412454226$

Arruda, M. A., \& Bigal, M. (2012b). Migraine and migraine subtypes in preadolescent children: Association with school performance. Neurology, 79, 1881-1888. doi:10.1212/ WNL.0b013e318271f812

Arruda, M. A., Bordini, C., Ciciarelli, M., \& Speciali, J. (2004). Decreasing the minimal duration of the attack to 1 hour: Is this sufficient to increase the sensitivity of the ICHD-II diagnostic criteria for migraine in childhood? The Journal of Headache and Pain, 5, 131-136. doi:10.1007/s10194-004-0081-x

Arruda, M. A., Guidetti, V., Galli, F., Albuquerque, R. C., \& Bigal, M. E. (2010a). Frequent headaches in the preadolescent pediatric population: A population-based study. Neurology, 74, 903-908. doi:10.1212/WNL.0b013e3181d561a2

Arruda, M. A., Guidetti, V., Galli, F., Albuquerque, R. C., \& Bigal, M. E. (2010b). Migraine, tension-type headache, and attention-deficit/hyperactivity disorder in childhood: A population-based study. Postgraduate Medicine, 122(5), 18-26. doi:10.3810/pgm.2010.09.2197

Associação Brasileira de empresas de pesquisa. (2009). Brazilian economic classification criteria. Retrieved from http://www. abep.org/criterio-brasil

Bellini, B., Arruda, M., Cescut, A., Saulle, C., Persico, A., Carotenuto, M., . . Guidetti, V. (2013). Headache and comorbidity in children and adolescents [Review]. The Journal of Headache and Pain, 14, 79. doi:10.1186/1129-2377-14-79

Bigal, M. E., Kurth, T., Santanello, N., Buse, D., Golden, W., Robbins, M., \& Lipton, R. B. (2010). Migraine and cardiovascular disease: A population-based study. Neurology, 74, 628-635. doi:10.1212/WNL.0b013e3181d0cc8b

Bigal, M. E., \& Lipton, R. B. (2006). Obesity is a risk factor for transformed migraine but not chronic tensiontype headache. Neurology, 67, 252-257. doi:10.1212/01. wnl.0000225052.35019.f9

Bruijn, J., Locher, H., Passchier, J., Dijkstra, N., \& Arts, W. F. (2010). Psychopathology in children and adolescents with migraine in clinical studies: A systematic review. Pediatrics, 126, 323-332. doi:10.1542/peds.2009-3293

Fasmer, O. B., Halmoy, A., Oedegaard, K. J., \& Haavik, J. (2011). Adult attention deficit hyperactivity disorder is associated with migraine headaches. European Archives of Psychiatry \& Clinical Neuroscience, 261, 595-602. doi:10.1007/s00406011-0203-9

Fleitlich, B., \& Goodman, R. (2001). Social factors associated with child mental health problems in Brazil: Cross sectional survey. British Medical Journal, 323, 599-600.

Fortes, I. S., Paula, C. S., Oliveira, M. C., Bordin, I. A., de Jesus Mari, J., \& Rohde, L. A. (2016). A cross-sectional study to assess the prevalence of DSM-5 specific learning disorders in representative school samples from the second to sixth grade in Brazil. European Child \& Adolescent Psychiatry, 25, 195207. doi:10.1007/s00787-015-0708-2

Gadermann, A. M., Alonso, J., Vilagut, G., Zaslavsky, A. M., \& Kessler, R. C. (2012). Comorbidity and disease burden in the National Comorbidity Survey Replication (NCS-R). Depression and Anxiety, 29, 797-806. doi:10.1002/da.21924

Galli, F., D’Antuono, G., Tarantino, S., Viviano, F., Borrelli, O., Chirumbolo, A., .. .Guidetti, V. (2007). Headache and recurrent abdominal pain: A controlled study by the means of the Child Behaviour Checklist (CBCL). Cephalalgia, 27, 211219. doi:10.1111/j.1468-2982.2006.01271.x

Gelfand, A. A., Fullerton, H. J., Jacobson, A., Sidney, S., Goadsby, P. J., Kurth, T., \& Pressman, A. (2015). Is migraine a risk factor for pediatric stroke? Cephalalgia, 35, 1252-1260. doi:10.1177/0333102415576222

Goncalves, D. A., Speciali, J. G., Jales, L. C., Camparis, C. M., \& Bigal, M. E. (2009). Temporomandibular symptoms, migraine, and chronic daily headaches in the population. Neurology, 73, 645-646. doi:10.1212/WNL.0b013e3181b389c2

Goodman, R. (1999). The extended version of the Strengths and Difficulties Questionnaire as a guide to child psychiatric caseness and consequent burden. Journal of Child Psychology and Psychiatry, and Allied Disciplines, 40, 791-799.

Goodman, R., Neves dos Santos, D., Robatto Nunes, A. P., Pereira de Miranda, D., Fleitlich-Bilyk, B., \& Almeida Filho, N. (2005). The Ilha de Mare study: A survey of child mental health problems in a predominantly African-Brazilian rural community. Social Psychiatry \& Psychiatric Epidemiology, 40, 11-17. doi:10.1007/s00127-005-0851-z

Guidetti, V., Galli, F., Fabrizi, P., Giannantoni, A. S., Napoli, L., Bruni, O., \& Trillo, S. (1998). Headache and psychiatric comorbidity: Clinical aspects and outcome in an 8-year follow-up study. Cephalalgia, 18, 455-462.

Headache Classification Subcommittee of the International Headache Society. (2004). The international classification of headache disorders: 2nd edition. Cephalalgia, 24(Suppl. 1), 9-160.

Inci, S. B., Ipci, M., Akyol Ardic, U., \& Ercan, E. S. (2016). Psychiatric comorbidity and demographic characteristics of 1,000 children and adolescents with ADHD in Turkey. Journal of Attention Disorders. Advance online publication. doi:10.1177/1087054716666954 
Instituto Brasileiro de Geografia e Estatística. (2009). Estatistica da Populacao Brasileira. Retrieved from http://www. ibge.gov.br/home/estatistica/populacao/estimativa2008/ POP2008_DOU.pdf

Jameson, N. D., Sheppard, B. K., Lateef, T. M., Vande Voort, J. L., He, J. P., \& Merikangas, K. R. (2016). Medical comorbidity of attention-deficit/hyperactivity disorder in US adolescents. Journal of Child Neurology, 31, 1282-1289.

Jonsson, U., Alaie, I., Lofgren Wilteus, A., Zander, E., Marschik, P. B., Coghill, D., \& Bolte, S. (2017). Annual Research Review: Quality of life and childhood mental and behavioural disorders-A critical review of the research [Review]. Journal of Child Psychology and Psychiatry, and Allied Disciplines, 58, 439-469. doi:10.1111/jcpp.12645

Kelley, S. A., Hartman, A. L., \& Kossoff, E. H. (2012). Comorbidity of migraine in children presenting with epilepsy to a tertiary care center. Neurology, 79, 468-473. doi:10.1212/ WNL.0b013e3182617113

Kwak, C., Vuong, K. D., \& Jankovic, J. (2003). Migraine headache in patients with Tourette syndrome. Archives of Neurology, 60, 1595-1598. doi:10.1001/archneur.60.11.1595

Lateef, T. M., Merikangas, K. R., He, J., Kalaydjian, A., Khoromi, S., Knight, E., \& Nelson, K. B. (2009). Headache in a national sample of American children: Prevalence and comorbidity. Journal of Child Neurology, 24, 536-543.

Lee, Y. C., Yang, H. J., Chen, V. C., Lee, W. T., Teng, M. J., Lin, C. H., \& Gossop, M. (2016). Meta-analysis of quality of life in children and adolescents with ADHD: By both parent proxy-report and child self-report using PedsQL. Research in Developmental Disabilities, (51-52), 160-172. doi:10.1016/j. ridd.2015.11.009

Lipton, R. B., Diamond, S., Reed, M., Diamond, M. L., \& Stewart, W. F. (2001). Migraine diagnosis and treatment: Results from the American Migraine Study II. Headache, 41, 638-645.

Mattos, P., Serra-Pinheiro, M. A., Rohde, L. A., \& Pinto, D. (2006). Apresentação de uma versão em português para uso no Brasil do instrumento MTA-SNAP-IV de avaliação de sintomas de transtorno do déficit de atenção/hiperatividade e sintomas de transtorno desafiador e de oposição [Presenting a Portuguese version for use in Brazil of the MTA-SNAP-IV instrument for assessing symptoms of Attention Deficit / Hyperactivity Disorder and Oppositional Defiant Disorder]. Rev Psiquiatr Rio Gd Sul, 28, 290-297.

Mincer, J. (1958). Investment in human capital and personal income distribution. Journal of Political Economy, 66, 281-302.

Ottman, R., \& Lipton, R. B. (1994). Comorbidity of migraine and epilepsy. Neurology, 44, 2105-2110.

Parisi, P., Verrotti, A., Paolino, M. C., Ferretti, A., Raucci, U., Moavero, R., . . Curatolo, P. (2014). Headache and attention deficit and hyperactivity disorder in children: Common condition with complex relation and disabling consequences [Review]. Epilepsy \& Behavior, 32, 72-75. doi:10.1016/j. yebeh.2013.12.028

Peng, Y. H., Chen, K. F., Kao, C. H., Chen, H. J., Hsia, T. C., Chen, C. H., \& Liao, W. C. (2016). Risk of migraine in patients with asthma: A nationwide cohort study. Medicine, 95(9), e2911. doi:10.1097/MD.0000000000002911
Polanczyk, G., de Lima, M. S., Horta, B. L., Biederman, J., \& Rohde, L. A. (2007). The worldwide prevalence of ADHD: A systematic review and metaregression analysis. The American Journal of Psychiatry, 164, 942-948.

Powers, S. W., Patton, S. R., Hommel, K. A., \& Hershey, A. D. (2003). Quality of life in childhood migraines: Clinical impact and comparison to other chronic illnesses. Pediatrics, 112(1, Pt. 1). e1-e5.

Queiroz, L. P., Peres, M. F., Kowacs, F., Piovesan, E. J., Ciciarelli, M. C., Souza, J. A., \& Zukerman, E. (2008). Chronic daily headache in Brazil: A nationwide population-based study. Cephalalgia, 28, 1264-1269.

Scherder, E. J., Rommelse, N. N., Broring, T., Faraone, S. V., \& Sergeant, J. A. (2008). Somatosensory functioning and experienced pain in ADHD-families: A pilot study. [Research Support, N.I.H., Extramural]. European Journal of Paediatric Neurology: EJPN: Official journal of the European Paediatric Neurology Society, 12, 461-469. doi:10.1016/j. ejpn.2007.11.004

Stickley, A., Koyanagi, A., Takahashi, H., \& Kamio, Y. (2016). ADHD symptoms and pain among adults in England. Psychiatry Research, 246, 326-331. doi:10.1016/j.psychres.2016.10.004

Strine, T. W., Okoro, C. A., McGuire, L. C., \& Balluz, L. S. (2006). The associations among childhood headaches, emotional and behavioral difficulties, and health care use. Pediatrics, 117, 1728-1735. doi:10.1542/peds.2005-1024

Thapar, A., \& Cooper, M. (2016). Attention deficit hyperactivity disorder. The Lancet, 387, 1240-1250. doi:10.1016/S01406736(15)00238-X

Treister, R., Eisenberg, E., Demeter, N., \& Pud, D. (2015) Alterations in pain response are partially reversed by methylphenidate (Ritalin) in adults with attention deficit hyperactivity disorder (ADHD). Pain Practice: The Official Journal of World Institute of Pain, 15, 4-11. doi:10.1111/papr.12129

Vannatta, K., Getzoff, E. A., Powers, S. W., Noll, R. B., Gerhardt, C. A., \& Hershey, A. D. (2008). Multiple perspectives on the psychological functioning of children with and without migraine. Headache, 48, 994-1004.

Varni, J. W., Limbers, C. A., \& Burwinkle, T. M. (2007). Impaired health-related quality of life in children and adolescents with chronic conditions: A comparative analysis of 10 disease clusters and 33 disease categories/severities utilizing the PedsQL 4.0 Generic Core Scales. Health and Quality of Life Outcomes, 5, 43.

Vingilis, E., Erickson, P. G., Toplak, M. E., Kolla, N. J., Mann, R. E., Seeley, J., . . .Daigle, D. S. (2015). Attention deficit hyperactivity disorder symptoms, comorbidities, substance use, and social outcomes among men and women in a Canadian sample. BioMed Research International, 2015, Article 982072. doi:10.1155/2015/982072

Virtanen, R., Aromaa, M., Koskenvuo, M., Sillanpaa, M., Pulkkinen, L., Metsahonkala, L., . . .Kaprio, J. (2004). Externalizing problem behaviors and headache: A follow-up study of adolescent Finnish twins. Pediatrics, 114, 981-987. doi:10.1542/peds.2003-1103-L

Zendarski, N., Sciberras, E., Mensah, F., \& Hiscock, H. (2016). A longitudinal study of risk and protective factors associated 
with successful transition to secondary school in youth with ADHD: Prospective cohort study protocol. BMC Pediatrics, 16, Article 20. doi:10.1186/s12887-016-0555-4

\section{Author Biographies}

Marco Antônio Arruda is a pediatric neurologist dedicated to the study of ADHD and headache in children. Since 2006, he and his team have headed a non-profit virtual academic network called Aprender Crianca (Learning the Child) (www.aprendercrianca. com.br) through which they develop epidemiological studies.
Renato Arruda is a 6th year medical student with special interest in ADHD and headache.

Vincenzo Guidetti is a full professor in University of Rome with seminal researches in the field of headache in children and child Psychiatry.

Marcelo Eduardo Bigal is a neurologist and a former professor of Albert Einstein College of Medicine (NY). He has published more than 220 papers in indexed journals on headache and migraine epidemiology. 